\title{
FEM ANALYSIS OF TWO DENTAL SCREW IMPLANTS POSITIONS FOR IMPROVING OSTEOINTEGRATION
}

\author{
NICA, V[eronica] M[ihaela]; VLASCEANU, D[aniel] \& GHEORGHIU, H[oria]
}

\begin{abstract}
The article presents the numeric analysis, using the finite element method (MEF) of the implant - maxillary assembly with the purpose of establishing the correct implantation position depending on the bone configuration in the implantation zone of the patient and on the implant (screw) type, efficient from the osteointegration point of view. For the investigation of biomechanical behaviour of the implant-bone interface two cases for analysis were considerate: case A ñ the implant is fixed only in the trabecular zone of the maxilla and case $B$ - the implant is fixed in the trabecular zone and also in the cortical zone of the maxilla. The implant screws are similar in terms of outside diameter but have different length, the state of strain and tension of the implant-bone interface were determined using ANSYS program, the results being compared. Keywords: dental implant, osteointegration, implant position, bone configuration, finite element analysis
\end{abstract}

\section{INTRODUCTION}

Oral implantology has emerged as a necessity for single, partially or completely edentulous patients, when physiognomic, functional and/or phonetic needs can not be satisfied by the classical methods of treatment [6].
Therefore, dental implants are used within the limits imposed by the availability of bone in three planes (sagittal, frontal and transverse) and by the edentulous ridges of the internal and external morphology in relation to structures such as the maxillary sinus, nasal cavity, mandibular canal, the hole between lower premolars, periosteal mucosa alveolar crest bone covering, etc.

Bone density available in an edentulous area, implant design, surgical approach, healing period and initial progressive bone requests during the prosthetic reconstruction have a major influence on the treatment plan.

Bone quality can be classified into four groups D1, D2, D3, and D4, Misch classification suggesting a composition, location and a measurable density reading (Hounsfield units) for each type of bone (Tab. 1) [5]. This classification was more recently supplemented with D5, which correspond to immature bone densitywith incomplete mineralization resulting from bone edentulous ridge augmentation.

\begin{tabular}{|c|c|c|}
\hline Bone type & Localisation & Description \\
\hline a) Dense cortical - D1 & $\begin{array}{l}\text { primarily in the } \\
\text { anterior mandible }\end{array}$ & $\begin{array}{l}\text { - almost all cortical bone, fewer intrinsic blood vessels and } \\
\text { depends for a significant portion of nutrient and blood supply on } \\
\text { the periosteal; } \\
\text { - the greatest bone to implant contact (BIC) exceptional initial } \\
\text { implant stability; } \\
\bullet \quad 1250 \text { Hounsfield units. }\end{array}$ \\
\hline b) Porous cortical - D2 & $\begin{array}{l}\text { the anterior and } \\
\text { posterior } \\
\text { mandible }\end{array}$ & $\begin{array}{l}\text { - thick crestal layer of cortical bone and coarse trabecular bone } \\
\text { underneath the cortical abundant intrinsic vascularisation due to its } \\
\text { coarse structure; } \\
\qquad \quad \text { offers a excellent BIC ratio; } \\
\text { - } 850-1250 \text { Hounsfield units. }\end{array}$ \\
\hline c) Coarse trabecular - D3 & $\begin{array}{l}\text { the anterior and } \\
\text { posterior maxilla } \\
\text { but also in the } \\
\text { posterior } \\
\text { mandible. }\end{array}$ & $\begin{array}{l}\text { - a porous crestal layer of cortical bone and fine trabecular } \\
\text { bone underneath the cortical bone; } \\
\text { - well vascularised and therefore aides in osteointegration; } \\
\text { - favourable to utilize implants with a titanium plasma spray } \\
\text { (TPS) or hydroxyapatite (HA) coating; } \\
\text { - 350-850Hounsfield units. }\end{array}$ \\
\hline d)Fine trabecular - D4 & $\begin{array}{l}\text { the posterior } \\
\text { maxilla }\end{array}$ & $\begin{array}{c}\text { - primarily fine trabecular bone, often the absence of cortical } \\
\text { bone; } \\
\text { - } \quad \text { the least amount of BIC; } \\
\text { - } 150-350 \text { Hounsfield units. }\end{array}$ \\
\hline
\end{tabular}

Tab. 1. Bone classification according to Misch [5] 



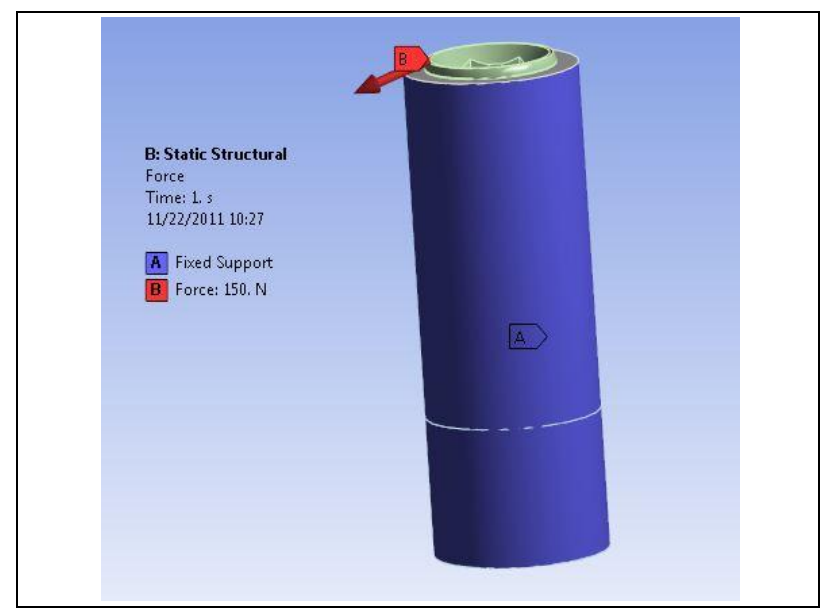

Fig. 4. The loading and locking mode - variant 1

After assignment of materials, the assembly was discretized in Ansys creating a network of 3D elements. Following the discretization process 53953 nodes and 30963 elements were obtained (Figure 3).

\subsection{The model constraints}

Due to the fact that trabecular zone is very small, the case when the implant comes out from it, was analysed. This way the model was fixed on the whole outer contour (Figure $5 \mathrm{a}, \mathrm{b}$ and $\mathrm{c}$ ) and as an external load was applied a force of $150 \mathrm{~N}$ under an angle of $15^{\circ}$.

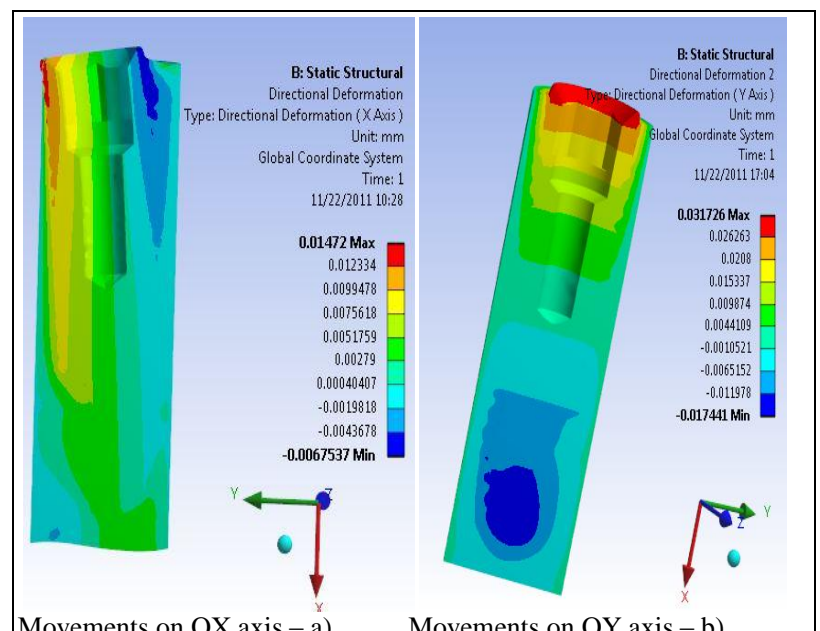

Movements on OY axis - b) Fig. 5. a,b. The movement distribution for case B, variant 1

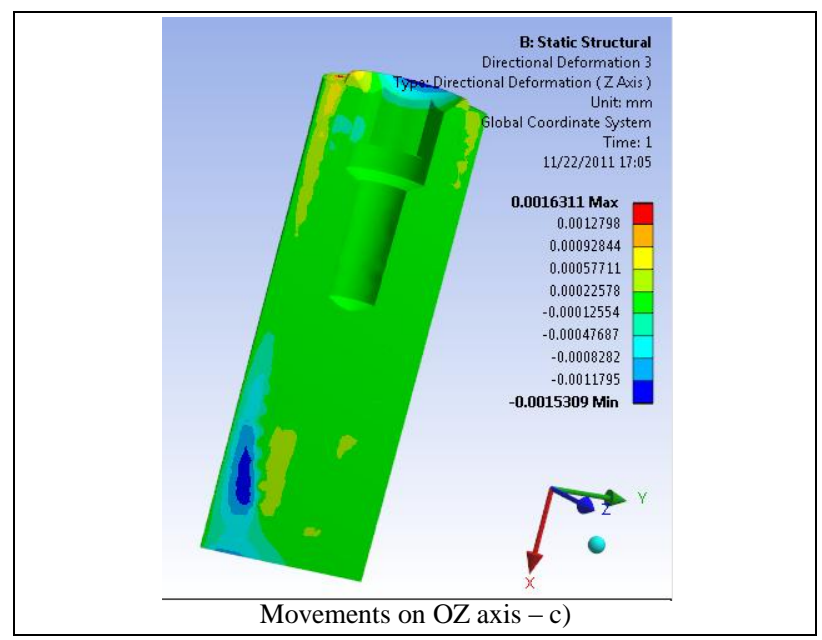

Fig. 5.c. The movement distribution for case B, variant 1

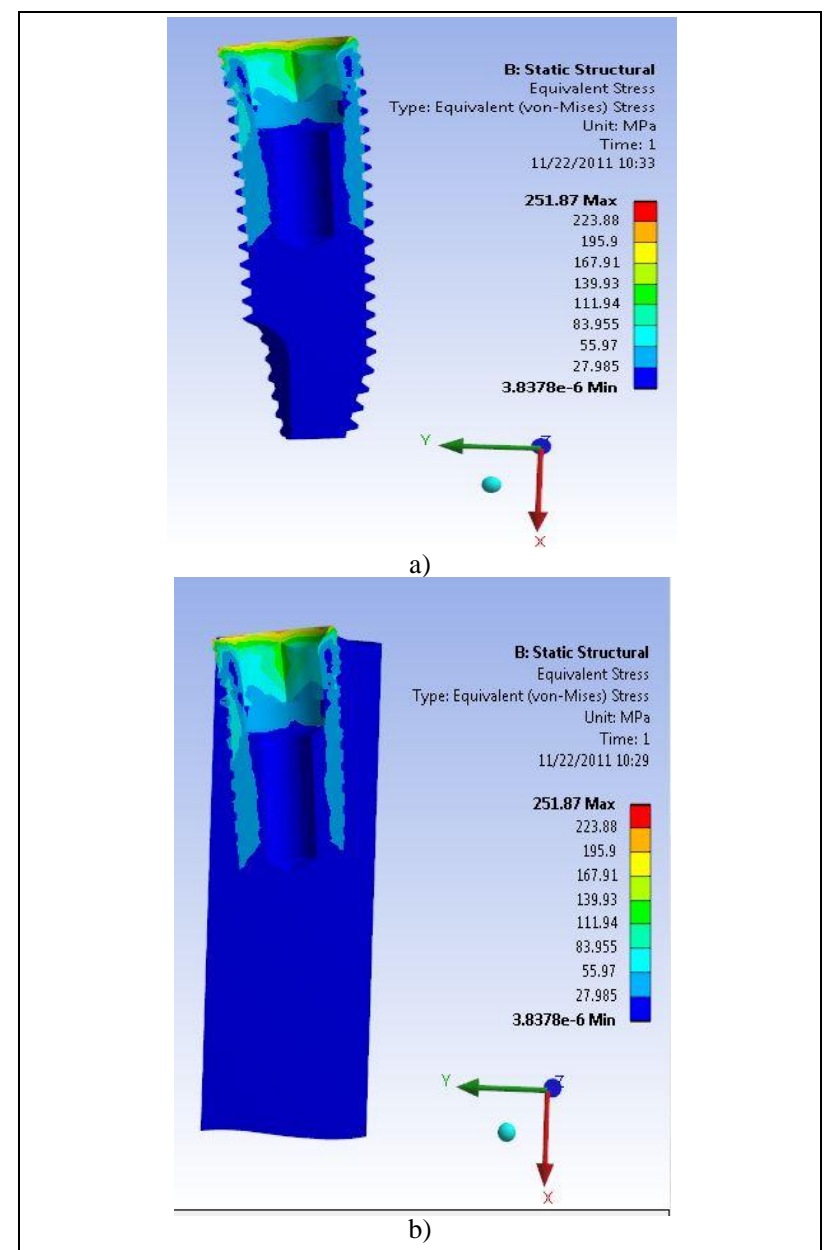

Fig. 6. Equivalent strain distribution in implant and assembly

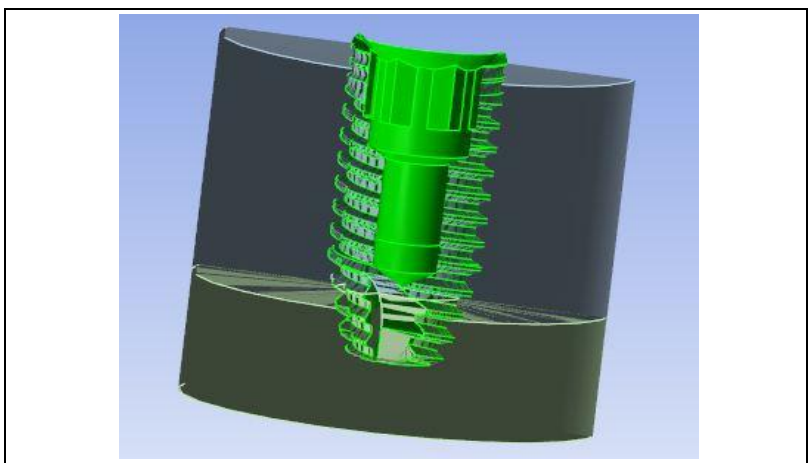

Fig. 7 The geometric model - variant 2

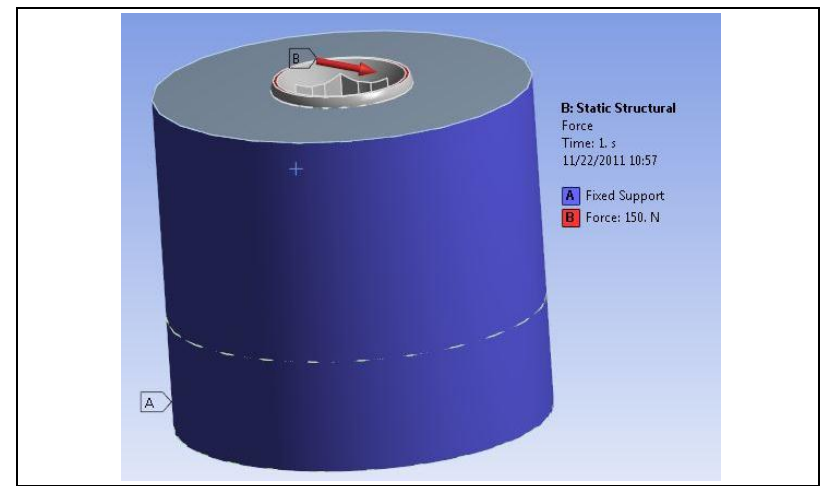

Fig. 8. Loading and locking mode - variant 2

Figure 7 presents the model in case B - variant 2 of the assembly consisting in: implant 2- trabecular + cortical bone. 


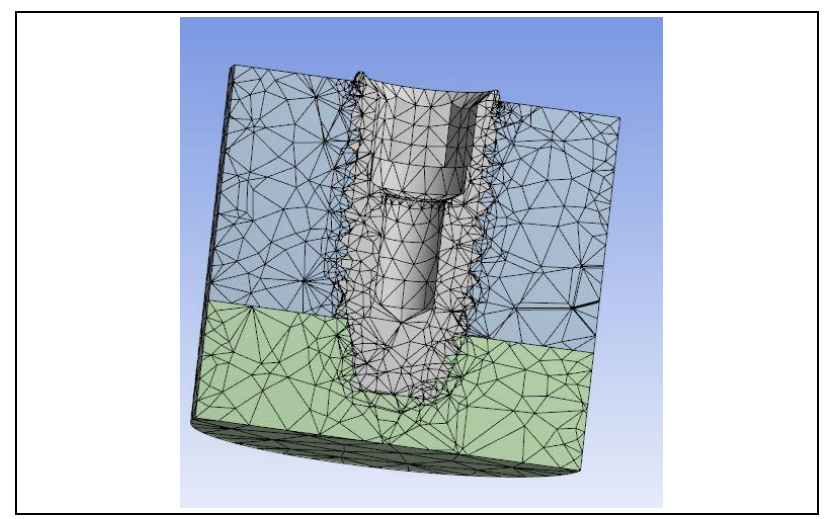

Fig. 9. Discretisation mode for case B, variant 2

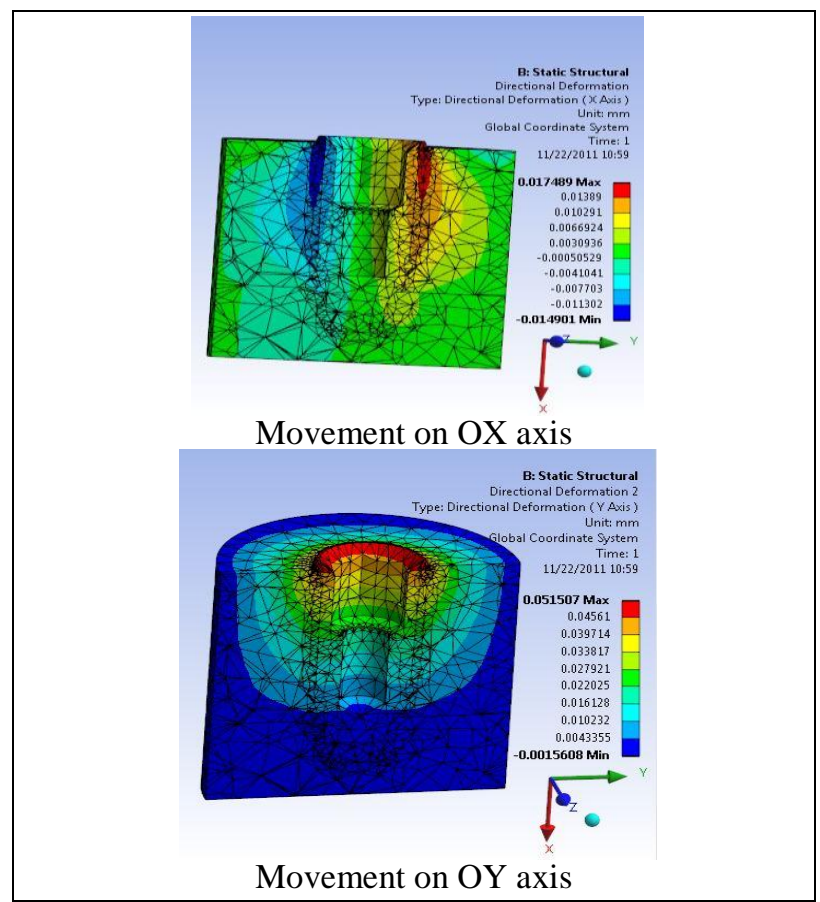

Fig. 10. The displacements distribution for case B, variant 2

The same properties of material and the same loading force were used also in case B, variant 2 for the assembly components (Figure 8). Following the discretization 43567 nodes and 24774 elements were obtained (Figure 9).

\section{CONCLUSIONS AND DISCUSSIONS}

The article presents a comparative analysis of two cases of implant (dental screw) - bone assemblies based on finite element analysis of the state of strain and tension using Ansys software. For each case, two variants were analysed, depending on the implant position (trabecular bone - case A, trabecular-cortical bone - case B). The results presented in figure 6 , as a result of applying of a load of $150 \mathrm{~N}$ (mastication force from incisor teeth zone), showed a small displacement of the implant on axial and lateral direction in upper part of the implant and in the peak zone.

Figure 7, representing the strain state distribution from implant-bone assembly, showed that the whole load is taken by the implant result a favourable osteointegration process.

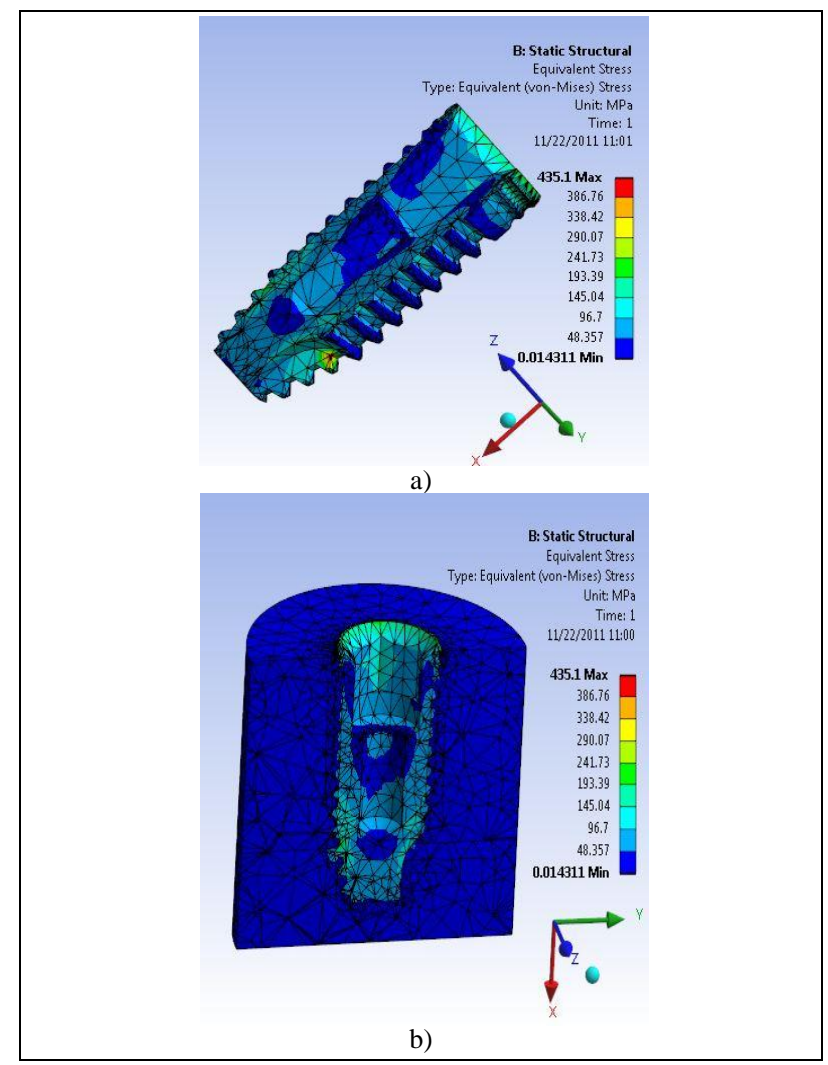

Fig. 11. Strain state from implant-bone assembly a) and b)

Analysing the maps in figure 10, it can be seen that for a shorter implant, a cortical bone graft can be made in order for the top of the implant to be fixed in cortical bone. Therefore, this can be considered as an optimal implantation solution in case when an implant with a longer length cannot be used.The same observation can be made by analysing the maps from figure 11: the implant is taking the load, which confirms our previous conclusion for establishing the correct implant position.

This paper is a study in the doctoral internship. In the future I will focus on modeling the modification form implants.

\section{REFERENCES}

[1] Comăneanu, R.M., Ghergic, D.L., Smătrea, O., Vlăsceanu, D., Miculescu, F., Târcolea, M., Microscopic (SEM, EDX) investigations on a new material/implant for dental use, Annals of DAAAM for 2009 \& Proceedings of the $20^{\text {th }}$ International Symposium, Volume 20, no. 1, ISSN 1726-9679, ISBN 978-3901509-70-4, pg. 1597-1598, 2009

[2] Weiss, C.M., Short and long-term bone maintenance surrounding fibro-osteal and osteal integrated dental implants, J OralImplanto 116:12, 1990

[3] Davies, J.E., Mechanism of endosseous integration. Int J Prosthodont; 11:391-401, 1998

[4] Herrmann, I., Lekholm, U., Holm S. et \& - Evaluation of patients and implant characteristics as potential prognosis factor for oral implant failures. Int J Oral Maxillofac Impl 20:220-230, 2005.

[5] Misch, C.E., Density of bone: effect on treatment plans, surgical approach, healing and progressive loading, Int J Oral Implant, 6:23-31, 1990

[6] Sarbu, I., Curs practic de implantologie orala, Ed.2, 2006

[7] Meijer, H.J.A., Kuper, J.H., Starmans, F.J.M., Bosman, F., Stress distribution around dental implants: Influence of superstructure, lenght of implants, height of mandible. J Prosthet Dent; 68: 96101, 1992 